ВІСНИК

ОДЕСЬКОГО НАЦІОНАЛЬНОГО

МОРСЬКОГО УНІВЕРСИТЕТУ

№ 2 (59), 2019
HERALD

OF THE ODESSA NATIONAL

MARITIME UNIVERSITY

№ 2 (59), 2019

УДК 674.047

JEL Classification C6

DOI 10.33082/2226-1915 -2-2019-135-154

\title{
ІДЕНТИФІКАЦІЯ ТЕПЛОГЦДРАВЛЧНИХ ХАРАКТЕРИСТИК КАНАЛІВ СКЛАДНОГО ПРОФІЛЮ
}

\author{
Т.Д. Панченко \\ старший викладач кафедри «Технічна кібернетика \\ та інформаційні технології ім. професора Р.В. Меркта» \\ tay_pan59@mail.ru
}

\section{B.I. Стародуб}

старший викладач кафедри «Технічна кібернетика та інформаційні технології ім. професора Р.В. Меркта» sval6236@gmail.com

\section{I.A. Тузова} доцент кафедри «Технічна кібернетика та інформаційні технології ім. професора Р.В. Меркта» irinatuzova@yandex.ru

\section{В.В. Челабчі}

ст старший викладач кафедри «Технічна кібернетика та інформаційні технології ім. професора Р.В. Меркта»

\section{vl_chel@ukr.net}

\section{В.М. Челабчі}

к.т.н. професор кафедри «Технічна кібернетика та інформаційні технології ім. професора Р.В. Меркта»

$$
\text { vn_chel@ukr.net }
$$

Одеський націіональний морський університет

Анотація. У статті розглядаються методики ідентифікації теплогідравлічних характеристик щілинних каналів складного профілю при ламінарному і перехідному режимах течії повітря.

Ідентифікація аеродинамічних характеристик здійснюється на базі натурного експерименту. Робочим середовищем в експерименті $\epsilon$ вода. При переході до залежностей для повітря використовується теорія подібності.

Дослідження теплопереносу в каналі здійснюється чисельним методом. Пропонується ефективна методика апроксимації рівнянь математичних моделей перенесення. Крім того використовується новий алгоритм спільного рішення рівнянь перенесення. Рішення завдань по моделюванню швидкості повітря і тиску проводиться ітерачійно. Отримане поле швидкості повітря дозволяє чисельним методом визначити поле температури.

() Панченко Т.Д., Стародуб В.І., Тузова І.А., Челабчі В.В., Челабчі В.М., 2019 
За результатами моделювання встановлюються критерійні залежності для опису теплообміну.

Ключові слова: ідентифікація, теплогідравлічні характеристики, канал, складний профіль.

\section{УДК 674.047}

JEL Classification C6

DOI 10.33082/2226-1915 -2-2019-135-154

\section{ИДЕНТИФИКАЦИЯ ТЕПЛОГИДРАВЛИЧЕСКИХ ХАРАКТЕРИСТИК КАНАЛОВ СЛОЖНОГО ПРОФИЛЯ}

\section{Т.Д. Панченко}

старший преподаватель кафедры «Техническая кибернетика и информационные технологии им. профессора Р.В. Меркта»

\section{tay_pan59@mail.ru}

В.И. Стародуб

старший преподаватель кафедры «Техническая кибернетика и информационные технологии им. профессора Р.В. Меркта» sval6236@gmail.com

\section{И.А. Тузова}

доцент кафедры «Техническая кибернетика

и информационные технологии им. профессора Р.В. Меркта» irinatuzova@yandex.ru

\section{В.В. Челабчи}

старший преподаватель кафедры «Техническая кибернетика и информационные технологии им. профессора Р.В. Меркта»

$$
\text { vl_chel@ukr.net }
$$

\section{В.Н. Челабчи}

к.т.н. професор кафедри «Техническая кибернетика и информационные технологии им. профессора Р.В. Меркта»

$$
\text { vn_chel@ukr.net }
$$

\section{Одесский национальный морской университет}

Аннотация. В статье рассматриваются методики идентификации теплогидравлических характеристик щчелевых каналов сложного профиля при ламинарном и переходном режимах течения воздуха.

Идентификаџия аэродинамических характеристик осуществляется на базе натурного эксперимента. Рабочей средой в эксперименте является вода. При переходе к зависимостям для воздуха используется теория подобия.

Исследование теплопереноса в канале осуществляется численным методом. Предлагается эффективная методика аппроксимации уравнений математических моделей переноса и используется новый алгоритм совместного решения уравнений переноса. Моделирование 
скорости воздуха и давления проводится итерационно. Полученое поле скорости воздуха позволяет численным методом определить поле температуры. По результатам моделирования устанавливаются критериальные зависимости для описания теплообмена.

Ключевые слова: идентификация, теплогидравлические характеристики, канал, сложнылй профиль.

UDC 674.047

JEL Classification C6

DOI 10.33082/2226-1915 -2-2019-135-154

\section{IDENTIFICATION OF HEAT AND HYDRAULIC CHARACTERISTICS OF CHANNELS OF COMPLEX PROFILE}

T.D. Panchenko

senior lecturer of the department

of «Technical Cybernetics named of the Professor R.V. Merct» tdp_1103@ukr.net

V.I. Starodub

senior lecturer of the department

of «Technical Cybernetics named of the Professor R.V. Merct» sval6236@gmail.com

\section{I.A. Tuzova}

Associate Professor of the department

of «Technical Cybernetics named of the Professor R.V. Merct» irinatuzova@yandex.ru

\section{V.V. Chelabchi}

senior lecturer of the department

of «Technical Cybernetics named of the Professor R.V. Merct»

$$
\text { vl_chel@ukr.net }
$$

\section{V.N. Chelabchi}

Ph. D. Professor of the department

of «Technical Cybernetics named of the Professor R.V. Merct»

vn_chel@ukr.net

\section{Odessa National Maritime University}

Abstract. The article discusses the methods for identifying the heathydraulic characteristics of the slotted channels of a complex profile in the case of laminar and transient modes of air flow.

The identification of aerodynamic characteristics is carried out on the basis of a full-scale experiment. The working medium in the experiment is water. In the transition to dependencies for air, similarity theory is used.

The study of heat transfer in the channel is carried out numerically. An effective method of approximation of the equations of mathematical transport models is proposed and a new algorithm for jointly solving transport equations 
is used. The solution of tasks on modeling air velocity and pressure is carried out iteratively. The obtained air velocity field allows us to determine the temperature field by a numerical method. According to the simulation results, criterion dependences are established for describing heat transfer.

Keywords: identification, thermal and hydraulic characteristics, channel, complex profile.

Вступ. Вірогідність інформації, отриманої при моделюванні технічних систем та їх елементів, в першу чергу залежить від того, наскільки докладно й адекватно використовувані математичні моделі описують процеси в об'єкті моделювання. Рішення багатьох прикладних задач вимагає детального дослідження пов'язаних процесів перенесення маси, імпульсу і енергії. Зазвичай, області визначення шуканих функцій мають складну конфігурацію (можуть бути багатозв'язаними), а математичні моделі відрізняються наявністю істотних нелінійностей. Слід врахувати, що для призначення оптимальних режимів функціонування об'єкта потрібно достовірне прогнозування поведінки досліджуваних процесів.

Аналіз існуючих способів виробництва холоду для комфортного кондиціювання повітря дозволяє виділити в якості перспективної екологічно чистої і економічної технології випарне охолодження повітря, коли в якості агента, що витрачається, використовується вода. Тому як об'єкт моделювання обрана установка охолодження повітря непрямого випарного типу [1;2].

Метою роботи $є$ розробка експериментально-розрахункового методу моделювання процесів переносу в розгалуженій системі каналів складного профілю.

Огляд літературних джерел. Моделюванню (експериментальному i чисельному) процесів переносу маси, імпульсу та енергії присвячено безліч робіт $[3 ; 5]$.

Останнім часом в різних теплотехнічних системах часто використовуються пластинчасті теплообмінники [6;7]. У ряді випадків використовуються системи каналів складної топології [8]. Для підвищення ефективності теплообмінників застосовуються різні турбулізатори $[9 ; 10]$. Розробляються методи розрахунку тепломасопереносу в каналах при їх вза-ємному впливі $[11 ; 12]$.

Проводиться моделювання процесів тепло і масопереносу в пристроях охолодження повітря непрямого випарного типу [13]. Відпрацьовуються методи моделювання подібних охолоджувачів повітря з метою оптимізації їх конструкції і режимів роботи [14].

На жаль, в літературних джерелах основна увага приділяється каналам типових конфігурацій, а у ряді випадків в охолоджувачах повітря канали нетипового профілю мають переваги. Крім того в довідниках в основному розглядаються турбулентні режими течії повітря, а в повітро- 
охолоджувачах використовуються ламінарні і перехідні режими руху повітря.

Постановка задачі. Функціонування охолоджувачів повітря засновано на використанні ефекту непрямого випарного охолоджування у розвиненій системі каналів змінного профілю. Основним апаратом $є$ тепломасообмінна насадка, утворена сукупністю водонепроникних пластин (плівок), покритих зволожуваним пористим матеріалом. Зовнішнє повітря поступає в сухі канали, де віно охолоджується за рахунок теплообміну з сухою поверхнею пластини. Частина його прямує до споживача, а частина, що залишилася, прямує у вологі канали, де воно насичується парами води, що випаровується 3 поверхні пористого матеріалу. На випаровування води відбирається тепло від повітря, що проходить в сухому каналі. Вода є робочим агентом, що витрачається [1]. Схему однієї модифікації охолоджувача повітря показано на рис. 1.
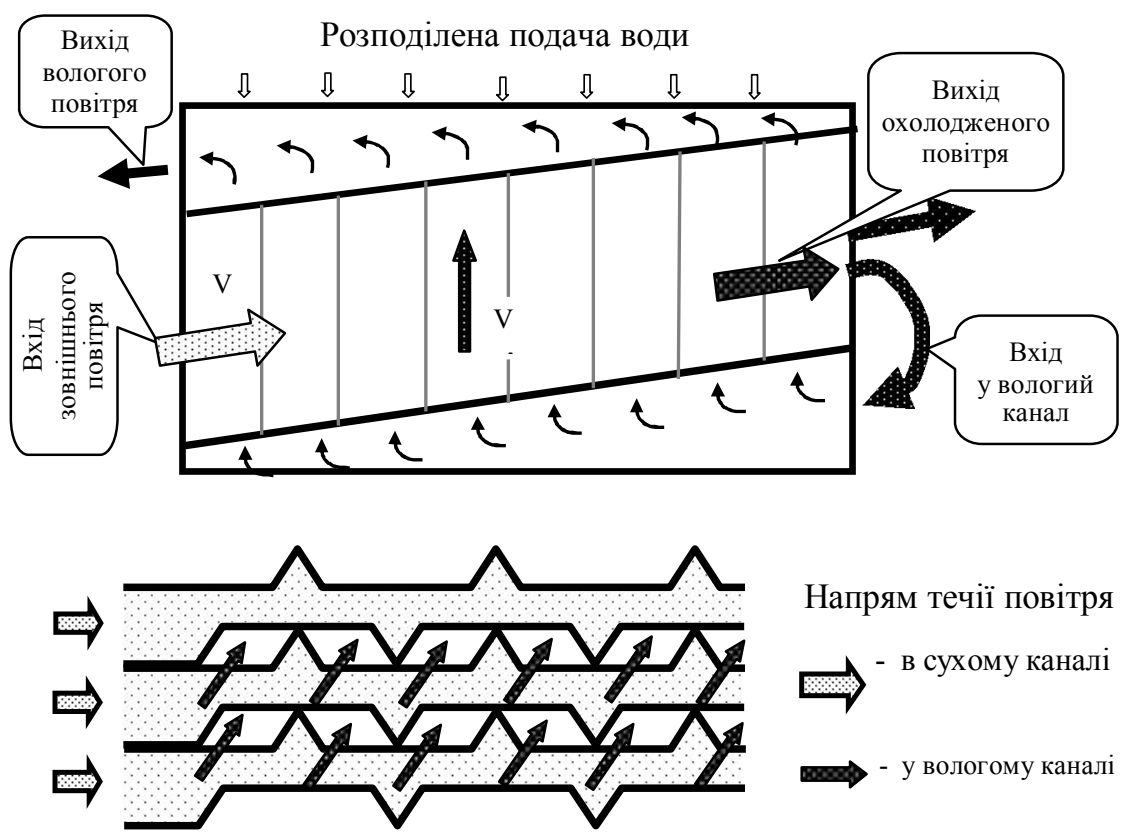

Рис. 1. Схема розподілу потоків повітря в охолоджувачі

Складність моделювання процесів в охолоджувачах повітря побічно-випарного типу полягає в тому, що теплообмінні матриці містять велике число каналів. Слід зазначити, що канали тепломасообмінних матриць (як сухі так і вологі) відрізняються малими конструктивними розмірами по зазору (1,5-2,0 мм) і ширині (15-25 мм). 
Для теплообмінників 3 розгалуженою системою каналів різного профілю істотним $є$ розподіл потоків робочих середовищ. Це великою мірою визначає ефективність пристрою. Для моделювання взаємозв'язаних процесів перенесення маси, імпульсу і тепла в системі каналів необхідно вирішити дві основні задачі: каналів;

- розрахунок розподілу потоків робочих середовищ в системі

- моделювання взаємозв'язаних процесів перенесення 3 урахуванням взаємодії робочих середовищ через стінки каналів.

Для розрахунків розподілу потоків створюється математична модель у вигляді системи нелінійних алгебраїчних рівнянь. Рішення системи нелінійних рівнянь можна отримати різними методами (наприклад [15] ). Модель течії в каналах створюється на основі феноменологічного підходу [3] з урахуванням довідкових даних [4; 5].

На жаль, для ряду каналів 3 нетрадиційною конфігурацією стінок довідкові дані відсутні. Тому доводиться проводити експериментальні дослідження з метою визначення реальних аеродинамічних характеристик каналів. Особливо складно досліджувати течію повітря в каналах з малим проміжком між стінками 1,5-2 мм. Це пояснюється складністю надійного виміру швидкості повітря в каналі. Тому пропонується проводити дослідження з водою, в якості робочого агента, а результати експерименту перераховувати для потоків повітря, використовуючи теорію подібності .

Особливі проблеми виникають при моделюванні процесів перенесення тепла і концентрації водяної пари в каналах з малим проміжком. Як модель зазвичай використовуються рівняння, що описують процеси перенесення в одновимірній постановці.

Але для каналів складної, нетрадиційної конфігурації в літературних джерелах відсутні залежності для розрахунку коефіцієнтів теплообміну і масообміну. Проведення натурних експериментів для визначення локальних значень коефіцієнтів обміну в щілинних каналах складного профілю вимагає значних витрат (наприклад, для створення і придбання прецизійних малогабаритних датчиків і реєструвальної апаратури). Тому розумним $\epsilon$ використання комп'ютерного моделювання процесів в подібних каналах 3 використанням сучасних інформаційних технологій для обробки результатів експериментів.

Ідентифікація аеродинамічних характеристик каналів. Під каналом розуміється сукупність елементів системи, через які проходить той самий масовий потік робочого середовища (газ або рідина). Характеристика каналу описується рівнянням (1)

$$
\Delta P=\zeta \cdot \frac{\rho \cdot V^{2}}{2}
$$


ВІСНИК

ОДЕСЬКОГО НАЦІОНАЛЬНОГО

МОРСЬКОГО УНІВЕРСИТЕТУ № 2 (59), 2019
HERALD

OF THE ODESSA NATIONAL

MARITIME UNIVERSITY № 2 (59), 2019

де $\Delta P$ - падіння (втрата) тиску по напрямку руху робочого середовища у каналі;

$V$ - визначальна швидкість руху середовища;

$\rho$ - щільність робочого середовища;

$\zeta$ - коефіцієнт опору каналу.

Для проведення натурного експерименту використовувалася установка, яка зображена на рис. 2. Як робочий агент в експериментальній установці використовується вода.

Вид моделі одного з каналів показаний на рис. 3.

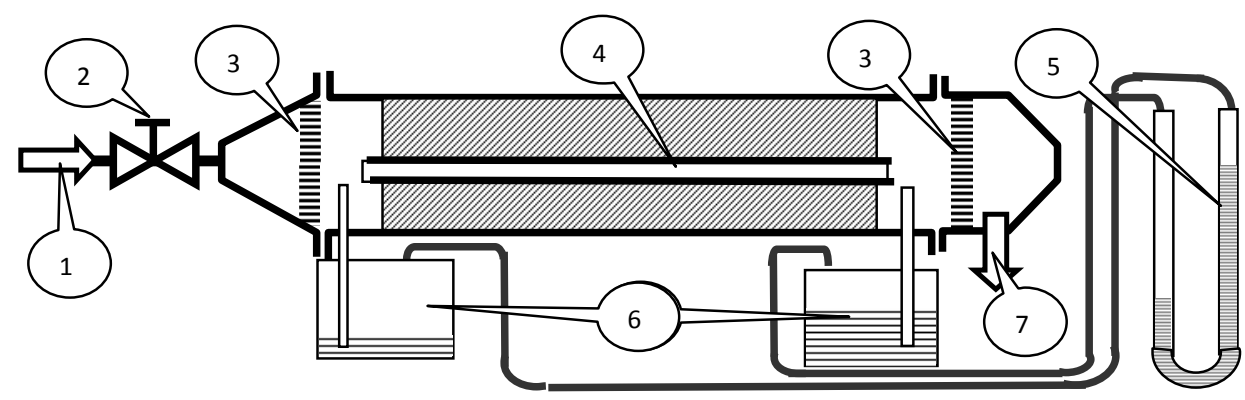

Рис. 2. Схема експериментальної установки:

1 - подача води; 2 - регулюючий вентиль; 3 - ножсові трати + сітка; 4 -модель каналу; 5 - ртутной манометр; 6- буферна ємність; 7 - злив води в вимірювальну ємність

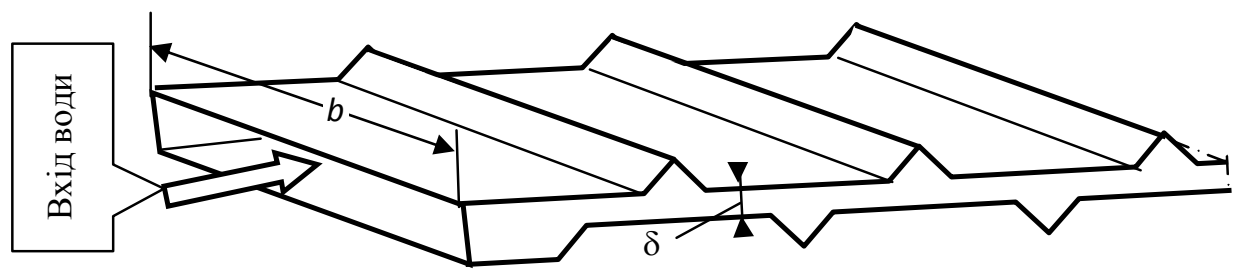

$\delta$ - характерний розмір каналу

Рис. 3. Модель каналу

Модель каналу міститься в робочий циліндр. Його обсяг обмежується ножовими гратами із сіткою. Модель продувається водою, яка подається через регулюючий вентиль. При дослідженні фіксувалися показання ртутного диференціального манометра $H g$ й відрізок часу, необхідного для заповнення мірної ємності $\Delta \tau$. 
Далі в статті індекс $w$ відносить величину до води, а індекс $a$ до повітря.

Визначальна (витратна) швидкість води в характерному перерізі каналу розраховується по формулі (2)

$$
V_{\mathrm{w}}=\frac{V_{e}}{\Delta \tau \cdot F_{\delta}},
$$

де $V_{\mathrm{w}}$ - витратна швидкість води в характерному перерізі каналу;

$V_{e}-$ об'єм води в мірній ємності;

$\Delta \tau-$ час заповнення мірної ємності;

$F_{\delta}-$ прохідна площа каналу в характерному перерізі.

Значення коефіцієнту опору моделі каналу $\zeta_{\mathrm{w}}$ (включаючи усі елементи каналу) розраховувалося по формулі (3)

$$
\zeta_{\mathrm{w}}=\frac{2 \cdot \Delta H_{g} \cdot \rho_{g}}{\rho_{\mathrm{w}} \cdot v_{\mathrm{w}}^{2}}
$$

де $\Delta H_{\mathrm{g}}, \rho_{\mathrm{g}}-$ відповідно показання ртутного манометра і щільність ртуті.

Багаторазове повторення експериментів істотно підвищує надійність визначення коефіцієнта опору для води $\zeta_{w}=f\left(v_{w}\right)$.

При обробці результатів експериментів використовується рівність значень чисел Рейнольдса $(R e)$ і Ейлера $(E u)(4)$

$$
\frac{V_{\mathrm{a}} \cdot \delta}{v_{\mathrm{a}}}=\frac{V_{\mathrm{w}} \cdot \delta}{v_{\mathrm{w}}}, \quad \frac{\Delta P_{\mathrm{a}}}{\rho_{\mathrm{a}} \cdot V_{\mathrm{a}}}=\frac{\Delta P_{\mathrm{w}}}{\rho_{\mathrm{w}} \cdot V_{\mathrm{w}}},
$$

де $V$ - визначальна швидкість руху середовища;

$\delta$ - характерний розмір;

$v$ - коефіцієнт кінематичної в'язкості середовища;

$\Delta P$ - падіння тиску по напрямку руху середовища.

Характерні розміри при бігу води й повітря в каналі однакові, тому можна записати (5)

$$
V_{\mathrm{a}}=V_{\mathrm{w}} \cdot \frac{v_{\mathrm{a}}}{v_{\mathrm{w}}}, \quad \Delta P_{\mathrm{a}}=\Delta P_{\mathrm{w}} \cdot \frac{\rho_{\mathrm{a}} \cdot V_{\mathrm{a}}^{2}}{\rho_{\mathrm{w}} \cdot V_{\mathrm{w}}{ }^{2}} .
$$

де $v, \rho$-відповідно коефіцієнт кінематичної в'язкості й щільність;

$\mathrm{w}, \mathrm{a}-$ iндекси, що відносять величину відповідно до води й повітря. 
Для перерахування значень величин, що відносяться до води в значення величин, що відносяться до повітря, можна використовувати залежність (6)

$$
\varsigma_{\mathrm{a}}=\varsigma_{\mathrm{w}} \cdot \frac{\rho_{\mathrm{a}} \cdot v_{\mathrm{a}}}{\rho_{\mathrm{w}} \cdot v_{\mathrm{w}}}
$$

Для однотипних, геометрично подібних каналів результати експериментів описуються залежністю (7)

$$
\varsigma=f\left(\operatorname{Re}, L_{\mathrm{o}}\right), \quad L_{\mathrm{o}}=L / \delta,
$$

де $L$ - довжина каналу.

На рис. 4 для типового каналу наведено графік залежності $\varsigma=f(R e)$.

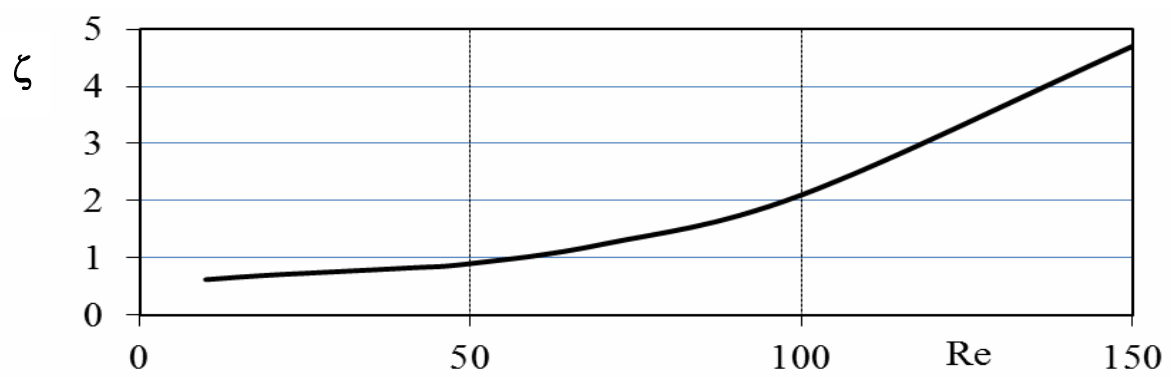

Рис. 4. Графік залежності $\varsigma=f(R e)$

При розрахунку розподілу потоків повітря в системі каналів зручно використати математичну модель каналу (8)

$$
\Delta P_{\mathrm{k}}=A_{\mathrm{k}} \cdot G_{\mathrm{k}},
$$

де $A_{\mathrm{k}}=\zeta_{\mathrm{k}} \cdot \rho /\left(2 \cdot F_{\mathrm{k}}^{2}\right) \cdot G_{\mathrm{k}}$,

$\mathrm{k}$ - індекс каналу.

Залежність (8) можна описати поліномом. У цьому випадку розрахунок розподілу потоків проводиться ітераційним шляхом [15] 3 уточненням значення $A_{\mathrm{k}}$ на кожній ітерації.

Дослідження теплообміну в каналі. У охолоджувачах повітря, як правило, використовуються щілинні канали, коли ширина каналу $\mathbf{b}$ значно більше проміжку $\delta$ (рис. 3). Тому при дослідженні процесів перенесення в таких плоских (щілинних) каналах допустимо користуватися 
моделями в двовимірній постановці. Оскільки, при виз-наченні коефіцієнтів масообміну у вологих каналах часто необхідно знати поле тиску повітря, слід розглядати моделі перенесення в природних змінних.

Найскладніший профіль в каналі сухого повітря. Профіль має періодичну форму (рис. 5).

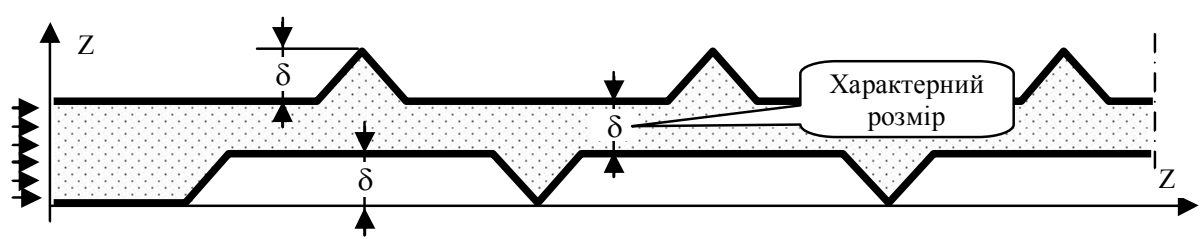

Рис. 5. Схема каналу сухого повітря

Процес плину описується в природних змінних рівнянням нерозривності (9) і рівнянням Нав'є-Стокса в проекціях на координатні осі (10)-(11). До цих рівнянь додається рівняння тиску (12). Орієнтація осей і векторів наведена на рис. 4. Шуканими $є$ поля компонентів вектора швидкості й поле тиску

$$
\begin{gathered}
\frac{\partial U}{\partial Y}+\frac{\partial W}{\partial Z}=0, \\
\frac{\partial U}{\partial \tau}+U \cdot \frac{\partial U}{\partial Y}+W \cdot \frac{\partial U}{\partial Z}=-\frac{1}{\rho} \frac{\partial P}{\partial Y}+v \cdot\left(\frac{\partial^{2} U}{\partial Y^{2}}+\frac{\partial^{2} U}{\partial Z^{2}}\right), \\
\frac{\partial W}{\partial \tau}+U \cdot \frac{\partial W}{\partial Y}+W \cdot \frac{\partial W}{\partial Z}=-\frac{1}{\rho} \cdot \frac{\partial P}{\partial Z}+v \cdot\left(\frac{\partial^{2} W}{\partial Y^{2}}+\frac{\partial^{2} W}{\partial Z^{2}}\right), \\
\frac{\partial^{2} P}{\partial Y^{2}}+\frac{\partial^{2} P}{\partial Z^{2}}=2 \cdot \rho \cdot\left(\frac{\partial W}{\partial Z} \cdot \frac{\partial U}{\partial Y}-\frac{\partial W}{\partial Y} \cdot \frac{\partial U}{\partial Z}\right),
\end{gathered}
$$

де $Y, Z, \tau$ - відповідно координати й час;

$U, W, P$ - компоненти вектора швидкості й тиск;

$\rho, v$ - щільність і коефіцієнт кінематичної в'язкості повітря.

Задача розщеплюється на дві підзадачі: визначення полів швидкості і визначення поля тисків. Узгодження рішень обумовлених підзадач здійснюється ітераційно (глобальні ітерації). Локальні ітерації використовуються при рішенні кожної з підзадач.

Для рішення задач у розглянутому підході використовується модифікований метод кінцевих різниць [16;17], у якому комплекс, що включає члени із другими й першими похідними апроксимується [18] по триточковій схемі (13) 


$$
\frac{\partial^{2} f}{\partial x^{2}}-D \cdot \frac{\partial f}{\partial x} \approx A 1 \cdot f_{\mathrm{i}-1}+A 2 \cdot f_{\mathrm{i}}+A 3 \cdot f_{\mathrm{i}+1} \text {. }
$$

Величина D може бути функцією рішення. Тоді ï значення уточнюється ітераційним методом (локальні ітерації). Розрахункові залежності для коефіцієнтів A1, А2, А3 можна одержати 3 аналітичного рішення рівняння виду (14) при постійному значенні правої частини на відрізку осі, обмеженому вузловими точками з індексами i-1 i i+1

$$
\frac{\partial^{2} f}{\partial x^{2}}-D \cdot \frac{\partial f}{\partial x}=\text { const } .
$$

Одночасно можна 3 аналітичного рішення (14) одержати аналогічну апроксимуючу залежність для першої похідної (15), що важливо при апроксимації рівняння нерозривності

$$
\frac{\partial f}{\partial x} \approx B 1 \cdot f_{\mathrm{i}-1}+B 2 f_{\mathrm{i}}+B 3 \cdot f_{\mathrm{i}+1},
$$

де

$$
\begin{gathered}
A 1=\frac{D \cdot \Delta x \cdot\left(C_{2}-C_{1}\right)}{C_{3}}, \quad A 2=-\frac{D \cdot \Delta x \cdot C_{2}}{C_{3}}, \quad A 3=\frac{D \cdot \Delta x \cdot C_{1}}{C_{3}}, \\
B 1=\frac{D \cdot \Delta x \cdot\left(C_{1}+1\right)-C_{2}+C_{1}}{C_{2}-2 C_{1}}, B 2=\frac{C_{2}-2 \cdot D \cdot \Delta x \cdot\left(C_{1}+1\right)}{C_{2}-2 C_{1}}, \\
B 3=\frac{D \cdot \Delta x \cdot\left(C_{1}+1\right)-C_{1}}{C_{2}-2 C_{1}}, \quad C_{1}=\exp (D \cdot \Delta x)-1, \\
C_{2}=\exp (2 \cdot D \cdot \Delta x)-1, \quad C_{3}=C_{2}-2 \cdot C_{1}, \quad \Delta x-\text { крок сітки. }
\end{gathered}
$$

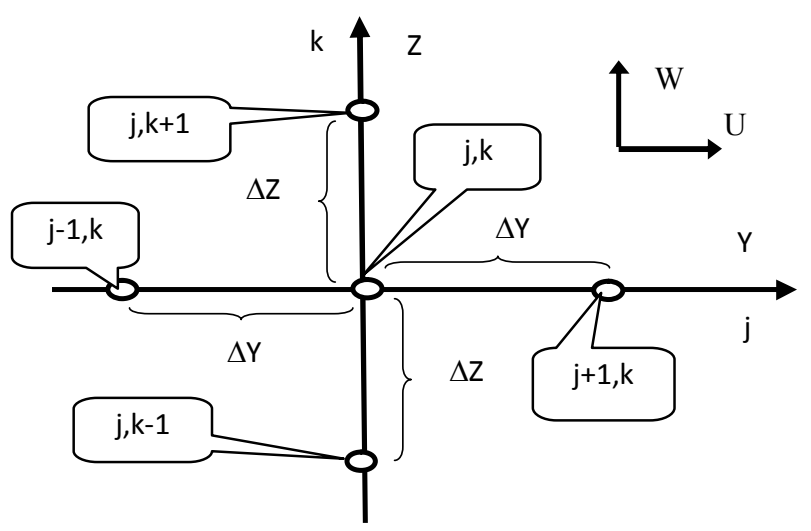

Рис. 6. Схема индексации 
Згідно 3 [13; 17] рівняння (10) та (11) записуються у вигляді (16) та (17).

$$
\begin{gathered}
\left(\frac{\partial^{2} U}{\partial Y^{2}}-D_{\mathrm{u}} \cdot \frac{\partial U}{\partial Y}\right)+\left(\frac{\partial^{2} U}{\partial Z^{2}}-D_{\mathrm{w}} \cdot \frac{\partial U}{\partial Z}\right)=\frac{1}{v \cdot \rho} \cdot \frac{\partial P}{\partial Y}+\frac{1}{v} \cdot \frac{\partial U}{\partial \tau}, \\
\left(\frac{\partial^{2} W}{\partial Y^{2}}-D_{\mathrm{u}} \cdot \frac{\partial W}{\partial Y}\right)+\left(\frac{\partial^{2} W}{\partial Z^{2}}-D_{\mathrm{w}} \cdot \frac{\partial W}{\partial Z}\right)=\frac{1}{v \cdot \rho} \cdot \frac{\partial P}{\partial Z}-\frac{1}{v} \cdot \frac{\partial W}{\partial \tau},
\end{gathered}
$$

де $D_{\mathrm{u}}=\frac{U}{v}, \quad D_{\mathrm{w}}=\frac{W}{v}$.

При різницевій апроксимації перших похідних і комплексів типу (13) одержимо (18)

$$
\begin{gathered}
\frac{\partial U}{\partial Y} \approx \frac{1}{\Delta Y} \cdot\left(B 1_{\mathrm{uy}} \cdot U_{\mathrm{j}-1, \mathrm{k}}+B 2_{\mathrm{uy}} \cdot U_{\mathrm{j}, \mathrm{k}}+B 3_{\mathrm{uy}} \cdot U_{\mathrm{j}+1, \mathrm{k}}\right), \\
\frac{\partial U}{\partial Z} \approx \frac{1}{\Delta Z} \cdot\left(B 1_{\mathrm{uz}} \cdot U_{j, k-1}+B 2_{\mathrm{uz}} \cdot U_{\mathrm{j}, \mathrm{k}}+B 3_{\mathrm{uz}} \cdot U_{\mathrm{j}, \mathrm{k}+1}\right), \\
\frac{\partial^{2} U}{\partial Y^{2}}-D_{\mathrm{u}} \cdot \frac{\partial U}{\partial Y} \approx \frac{1}{(\Delta Y)^{2}} \cdot\left(A 1_{\mathrm{uy}} \cdot U_{\mathrm{j}-1, \mathrm{k}}+A 2_{\mathrm{uy}} \cdot U_{\mathrm{j}, \mathrm{k}}+A 3_{\mathrm{uy}} \cdot U_{\mathrm{j}+1, \mathrm{k}}\right) \\
\frac{\partial^{2} U}{\partial Z^{2}}-D_{\mathrm{w}} \cdot \frac{\partial U}{\partial Z} \approx \frac{1}{(\Delta Z)^{2}} \cdot\left(A 1_{\mathrm{uz}} \cdot U_{\mathrm{j}, \mathrm{k}-1}+A 2_{\mathrm{uz}} \cdot U_{\mathrm{j}, \mathrm{k}}+A 3_{\mathrm{uz}} \cdot U_{\mathrm{j}, \mathrm{k}+1}\right), \\
\frac{\partial^{2} W}{\partial Y^{2}}-D_{\mathrm{u}} \cdot \frac{\partial W}{\partial Y} \approx \frac{1}{(\Delta Y)^{2}} \cdot\left(A 1_{\mathrm{wy}} \cdot W_{\mathrm{j}-1, \mathrm{k}}+A 2_{\mathrm{wy}} \cdot W_{\mathrm{j}, \mathrm{k}}+A 3_{\mathrm{wy}} \cdot W_{\mathrm{j}+1, \mathrm{k}}\right) \\
\frac{\partial^{2} W}{\partial Z^{2}}-D_{\mathrm{w}} \cdot \frac{\partial W}{\partial Z} \approx \frac{1}{(\Delta Z)^{2}} \cdot\left(A 1_{\mathrm{wz}} \cdot W_{\mathrm{j}, \mathrm{k}-1}+A 2_{\mathrm{wz}} \cdot W_{\mathrm{j}, \mathrm{k}}+A 3_{\mathrm{wz}} \cdot W_{\mathrm{j}, \mathrm{k}+1}\right)
\end{gathered}
$$

При апроксимації членів рівнянь використовується також (18).

$$
\begin{array}{rrr}
\frac{\partial P}{\partial Y}=\frac{\left(P_{\mathrm{j}+1, \mathrm{k}}-P_{\mathrm{j}-1, \mathrm{k}}\right)}{2 \cdot \Delta Y}, & \frac{\partial P}{\partial Z}=\frac{\left(P_{\mathrm{j}, \mathrm{k}+1}-P_{\mathrm{j}, \mathrm{k}-1}\right)}{2 \cdot \Delta Y}, \\
\frac{\partial U}{\partial \tau}=\frac{U_{\mathrm{j}, \mathrm{k}}-U_{\mathrm{j}, \mathrm{k}}^{*}}{\Delta \tau}, & \frac{\partial W}{\partial \tau}=\frac{W_{\mathrm{j}, \mathrm{k}}-W_{\mathrm{j}, \mathrm{k}}^{*}}{\Delta \tau} .
\end{array}
$$

Індекс * відносить величину до попереднього моменту часу.

Систему рівнянь (9)-(11) можна відобразити системою алгебраїчних рівнянь в кінцевих різницях (20). 
де

$$
\begin{gathered}
U_{j, k} \cdot a 1+W_{j, k} \cdot b 1=c 1, \\
U_{j, k} \cdot a 2+W_{j, k} \cdot b 2=c 2, \\
U_{j, k} \cdot a 3+W_{j, k} \cdot b 3=c 3,
\end{gathered}
$$

$a 1=B 2_{\text {uy }} / \Delta Y, \quad b 1=B 2_{\text {wz }} / \Delta Z$,

$$
c 1=-\frac{1}{\Delta Y} \cdot\left(B 1_{\mathrm{uy}} \cdot U_{\mathrm{j}-1, \mathrm{k}}+B 3_{\mathrm{uy}} \cdot U_{\mathrm{j}+1, \mathrm{k}}\right)-\frac{1}{\Delta Z} \cdot\left(B 1_{\mathrm{wz}} \cdot W_{\mathrm{j}, \mathrm{k}-1}+B 3_{\mathrm{wz}} \cdot W_{\mathrm{j}, \mathrm{k}+1}\right),
$$$$
a 2=A 2_{\mathrm{uy}}+A 2_{\mathrm{uz}}-(\Delta Z)^{2} /(v \cdot \Delta \tau), \quad \mathrm{b} 2=0,
$$$$
c 2=-\left(A 1_{\mathrm{uy}} \cdot U_{\mathrm{j}-1, \mathrm{k}}+A 3_{\mathrm{uy}} \cdot U_{\mathrm{j}+1, \mathrm{k}}\right)-\left(A 1_{\mathrm{uz}} \cdot U_{\mathrm{j}, \mathrm{k}-1}+A 3_{\mathrm{uz}} \cdot U_{\mathrm{j}, \mathrm{k}+1}\right)+
$$$$
+\Delta Z \cdot\left(P_{\mathrm{j}+1, \mathrm{k}}-P_{\mathrm{j}-1, \mathrm{k}}\right) /(2 \cdot v \cdot \rho)-(\Delta Z)^{2} \cdot U_{\mathrm{j}, \mathrm{k}}^{*} /(v \cdot \Delta \tau),
$$$$
a 3=0, \quad b 3=A 2_{u y}+A 2_{u z}-(\Delta Z)^{2} /(v \cdot \Delta \tau),
$$

$c 3=-\left(A 1_{\mathrm{uy}} \cdot W_{\mathrm{j}-1, \mathrm{k}}+A 3_{\mathrm{uy}} \cdot W_{\mathrm{j}+1, \mathrm{k}}\right)-\left(A 1_{\mathrm{uz}} \cdot W_{\mathrm{j}, \mathrm{k}-1}+A 3_{\mathrm{uz}} \cdot W_{\mathrm{j}, \mathrm{k}+1}\right)+$ $+\Delta Y \cdot\left(P_{\mathrm{j}, \mathrm{k}+1}-P_{\mathrm{j}, \mathrm{k}-1}\right) /(2 \cdot v \cdot \rho)-(\Delta Y)^{2} \cdot W_{\mathrm{j}, \mathrm{k}}^{*} /(v \cdot \Delta \tau)$,

Система лінійних алгебраїчних рівнянь (19) переозначена. Однак мінімізуючи функціонал $\delta$ можна переозначену систему (19) привести до системи двох квазілінійних рівнянь (20)

$$
\begin{aligned}
& \delta=\left(U_{\mathrm{j}, \mathrm{k}} \cdot a 1+W_{\mathrm{j}, \mathrm{k}} \cdot b 1-c 1\right)^{2}+\left(U_{\mathrm{j}, \mathrm{k}} \cdot a 2+W_{\mathrm{j}, \mathrm{k}} \cdot b 2-c 2\right)^{2}+ \\
& +\left(U_{\mathrm{j}, \mathrm{k}} \cdot a 3+W_{\mathrm{j}, \mathrm{k}} \cdot b 3-c 3\right)^{2} . \\
& \frac{\partial \delta}{\partial U_{\mathrm{j}, \mathrm{k}}}=2 \cdot a 1 \cdot\left(U_{\mathrm{j}, \mathrm{k}} \cdot a 1+W_{\mathrm{j}, \mathrm{k}} \cdot b 1-c 1\right)+2 \cdot a 2 \cdot\left(U_{\mathrm{j}, \mathrm{k}} \cdot a 2+W_{\mathrm{j}, \mathrm{k}} \cdot b 2-c 2\right)+ \\
& +2 \cdot a 3 \cdot\left(U_{\mathrm{j}, \mathrm{k}} \cdot a 3+W_{\mathrm{j}, \mathrm{k}} \cdot b 3-c 3\right)=0 . \\
& \frac{\partial \delta}{\partial W_{\mathrm{j}, \mathrm{k}}}=2 \cdot b 1 \cdot\left(U_{\mathrm{j}, \mathrm{k}} \cdot a 1+W_{\mathrm{j}, \mathrm{k}} \cdot b 1-c 1\right)+2 \cdot b 2 \cdot\left(U_{\mathrm{j}, \mathrm{k}} \cdot a 2+W_{\mathrm{j}, k} \cdot b 2-c 2\right)+ \\
& +2 \cdot b 3 \cdot\left(U_{\mathrm{j}, \mathrm{k}} \cdot a 3+W_{\mathrm{j}, \mathrm{k}} \cdot b 3-c 3\right)=0 . \\
& U_{\mathrm{j}, \mathrm{k}} \cdot A_{1}+W_{\mathrm{j}, \mathrm{k}} \cdot A_{2}=A_{3}, \\
& U_{\mathrm{j}, \mathrm{k}} \cdot A_{2}+W_{\mathrm{j}, \mathrm{k}} \cdot A_{1}=A_{4}, \\
& A_{3}=a 1 \cdot c 1+a 2 \cdot c 2+a 3 \cdot c 3 \text {, } \\
& A_{4}=b 1 \cdot c 1+b 2 \cdot c 2+b 3 \cdot c 3 \text {. }
\end{aligned}
$$


Отриману систему квазілінійних алгебраїчних рівнянь зручно вирішувати одним із прямих методів, уточнюючи на кожній локальній ітерації значення коефіцієнтів а1, а2 ... с2, с3.

Рішення рівняння (12) проводиться 3 використанням класичної триточкової різницевої схеми (22)

$$
P_{\mathrm{j}, \mathrm{k}}=\frac{1}{2 \cdot\left(\Delta Z^{2}+\Delta Y^{2}\right)}\left(\begin{array}{l}
\Delta Z^{2} \cdot\left(P_{\mathrm{j}-1, \mathrm{k}}+P_{\mathrm{j}+1, \mathrm{k}}\right)+\Delta Y^{2} \cdot\left(P_{\mathrm{j}, \mathrm{k}-1}+P_{\mathrm{j}, \mathrm{k}+1}\right)+ \\
+\frac{\rho \cdot \Delta Z \cdot \Delta Y}{2} \cdot\left(\begin{array}{l}
\left(U_{\mathrm{j}, \mathrm{k}+1}-U_{\mathrm{j}, \mathrm{k}-1}\right) \cdot\left(W_{\mathrm{j}+1, \mathrm{k}}-W_{\mathrm{j}-1, \mathrm{k}}\right)- \\
-\left(W_{\mathrm{j}, \mathrm{k}+1}-W_{\mathrm{j}, \mathrm{k}-1}\right) \cdot\left(U_{\mathrm{j}+1, \mathrm{k}}-U_{\mathrm{j}-1, \mathrm{k}}\right)
\end{array}\right)
\end{array}\right) .
$$

Реалізація граничних умов на стінках каналу, як правило, не викликає ускладнень. Використовуються умови прилипання й непротікання $W=0, U=0$.

На всіх твердих стінках, що не деформуються, реалізуються умови

$$
\partial P / \partial N=0
$$

де $N$-нормаль до поверхні.

Тиски на вході і виході каналу і швидкість повітря на вході в канал приймаються відповідно до результатів рішення задачі розподілу потоків повітря по каналах.

Теплоперенос у каналі описується рівнянням (23)

$$
\frac{{ }^{c} p \cdot \rho}{\lambda} \cdot\left(\frac{\partial T}{\partial \tau}+U \cdot \frac{\partial T}{\partial Y}+W \cdot \frac{\partial T}{\partial Z}\right)=\left(\frac{\partial^{2} T}{\partial Y^{2}}+\frac{\partial^{2} T}{\partial Z^{2}}\right),
$$

де $\mathrm{cp}, \lambda$ - відповідно питома теплоємність та коефіцієнт теплопровідності повітря.

Рівняння (23) приводиться до вигляду (24)

$$
\left(\frac{\partial^{2} T}{\partial Y^{2}}-D_{\mathrm{u}} \cdot \frac{\partial T}{\partial Y}\right)+\left(\frac{\partial^{2} T}{\partial Z^{2}}-D_{\mathrm{w}} \cdot \frac{\partial T}{\partial Z}\right)=-\frac{\partial T}{\partial \tau} \cdot \frac{c_{p} \cdot \rho}{\lambda},
$$

де $D_{\mathrm{u}}=U \cdot \frac{c_{p} \cdot \rho}{\lambda}, D_{\mathrm{w}}=W \cdot \frac{c_{p} \cdot \rho}{\lambda}$.

Використовується апроксимація

$$
\begin{gathered}
\frac{\partial^{2} T}{\partial Y^{2}}-D_{\mathrm{u}} \cdot \frac{\partial T}{\partial Y} \approx \frac{1}{(\Delta Y)^{2}} \cdot\left(A 1_{\mathrm{ty}} \cdot T_{\mathrm{j}-1, \mathrm{k}}+A 2_{\mathrm{ty}} \cdot T_{\mathrm{j}, \mathrm{k}}+A 3_{\mathrm{ty}} \cdot T_{\mathrm{j}+1, \mathrm{k}}\right), \\
\frac{\partial^{2} T}{\partial Z^{2}}-D_{\mathrm{w}} \cdot \frac{\partial T}{\partial Z} \approx \\
\frac{1}{(\Delta Z)^{2}} \cdot\left(A 1_{\mathrm{tz}} \cdot T_{\mathrm{j}, \mathrm{k}-1}+A 2_{\mathrm{tz}} \cdot T_{\mathrm{j}, \mathrm{k}}+A 3_{\mathrm{tz}} \cdot T_{\mathrm{j}, \mathrm{k}+1}\right), \\
\partial T / \partial \tau=\left(T_{\mathrm{j}, \mathrm{k}}-T_{\mathrm{j}, \mathrm{k}}^{*}\right) / \Delta \tau .
\end{gathered}
$$


Коефіцієнти $D_{u}, D_{w}$ і $A 1-A 3$ розраховуються згідно (13) та ітераційно уточнюються в процесі рішення.

Температурне поле потоку моделюється з використанням (25).

$$
T_{\mathrm{j}, \mathrm{k}}=\frac{\left[\begin{array}{l}
\left(A 1_{\mathrm{ty}} \cdot T_{\mathrm{j}-1, \mathrm{k}}+A 3_{\mathrm{ty}} \cdot T_{\mathrm{j}+1, \mathrm{k}}\right) /(\Delta Y)^{2}+ \\
+\left(A 1_{\mathrm{tz}} \cdot T_{\mathrm{j}, \mathrm{k}-1}+A 3_{\mathrm{tz}} \cdot T_{\mathrm{j}, \mathrm{k}+1}\right) /(\Delta Z)^{2}-\frac{{ }^{c} p \cdot \rho}{\lambda \cdot \Delta \tau} \cdot T_{\mathrm{j}, \mathrm{k}}^{*}
\end{array}\right]}{\left(\frac{A 2_{\mathrm{ty}}}{(\Delta Y)^{2}}+\frac{A 2_{\mathrm{tz}}}{(\Delta Z)^{2}}-\frac{c p \cdot \rho}{\lambda \cdot \Delta \tau}\right)} .
$$

На першому етапі досліджень проводиться визначення полів швидкості і тиску. При цьому забезпечується ітераційне узгодження результатів моделювання, як поля швидкості так і тиску. На другому етапі здійснюється моделювання температурного поля повітря в каналі 3 використанням отриманого раніше поля швидкості.

При моделюванні процесів перенесення в розгалуженій системі каналів повітроохолоджувача переважно використовуються моделі теплопереносу в одновимірній постановці [19]. Тому знання коефіцієнтів теплообміну (особливо для каналів нетипової конфігурації) украй потрібні.

Задавшись температурою стінки каналу і розподілом середньої по перерізу температури повітря по довжині каналу можна визначити залежність ефективного коефіцієнта теплообміну від числа Re по довжині каналу. (26).

Ефективний коефіцієнт теплообміну визначається по залежності

$$
G \cdot c_{p} \cdot \frac{d T}{d Y}=\alpha \cdot \Pi \cdot\left(T_{\mathrm{s}}-T\right),
$$

де $T, T_{s}$ - відповідно середня по перерізу температура повітря та температура стінки;

$\alpha$ - ефективний коефіцієнт теплообміну;

$c_{\mathrm{p}}$ - питома теплоємність повітря;

$\Pi$ - визначальний периметр;

$G$ - розрахункова масова витрата повітря.

При розрахунках проводилося згладжування [20] залежностей $\mathrm{Ts}=\mathrm{f}(\mathrm{Y})$ i $\alpha=\mathrm{f}(\mathrm{Y})$ с подальшою апроксимацією поліномами. Для узагальнення результатів використовуються залежності $\mathrm{Nu}$ від Re

$$
\mathrm{Nu}=\alpha \cdot \delta / \lambda, \quad \mathrm{Re}=V \cdot \delta / \nu,
$$

де $\quad \lambda-$ коефіцієнт теплопровідності повітря;

$v$ - коефіцієнт кінематичної в'язкості повітря;

$V$ - середня (розрахункова) швидкість в характерному перерізі каналу. 
ВІСНИК

ОДЕСЬКОГО НАЦІОНАЛЬНОГО

МОРСЬКОГО УНІВЕРСИТЕТУ

№ 2 (59), 2019
HERALD

OF THE ODESSA NATIONAL

MARITIME UNIVERSITY

№ 2 (59), 2019

Результати досліджень для одного каналу (рис. 4) наведені у рис. 7.

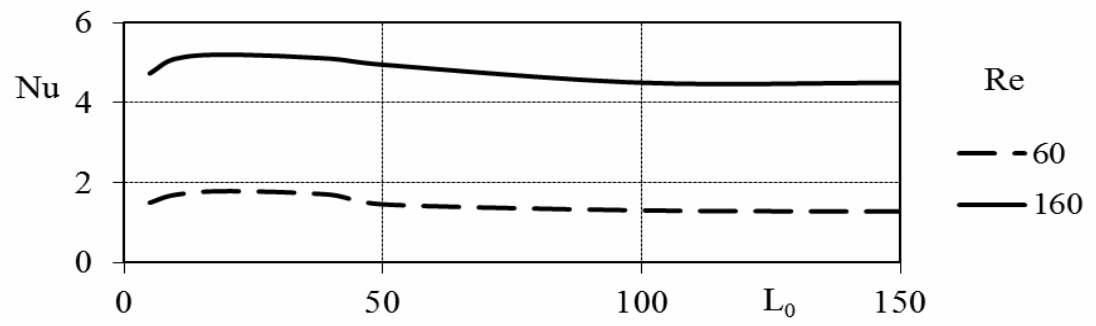

Рис. 7. Зміна числа Нусельта по довжині каналу

Типове поле швидкості повітря в каналі приведене на рис. 8.

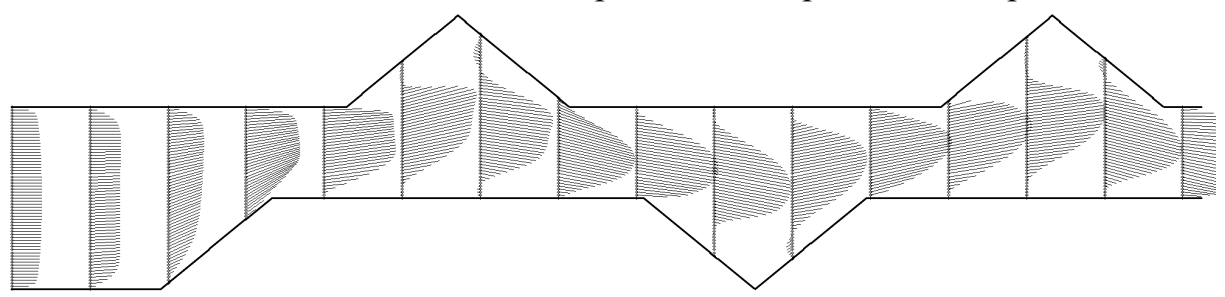

Рис. 8. Поле швидкості при перехідному режимі, щзо розвивається

Висновки. Пропоновані методики ідентифікації аеродинамічних і теплових характеристик щілинних каналів нетипового профілю можуть використовуватися для організації моделювання пов'язаних процесів переносу при ламінарних і перехідних режимах течії. Розглянуті підходи дозволяють прогнозувати характеристики каналів як для газоподібних так для рідких робочих середовищ. Методики орієнтовані на дослідження теплообмінних пристроїв зі складною розгалуженою системою каналів.

\section{СПИСОК ЛІТЕРАТУРИ}

1. Дорошенко А.В. Новое поколение систем кондиционирования воздуха на основе комбинированных испарительных охладителей / А.В. Дорошенко В.Х. Кириллов, О.В. Ефимова, А.А. Климчук // Холодильная техника и технология. 2000. №

2. Chelabshi68..N.. Ecologically clean cool-production on ships / R.V. Merkt, V.N. Chelabchi // Proceedings of the 6-th Congress of the IMAM. Varna, Bulgaria, 1993. V.3. P.173-179.

3. Чепурний М.М. Розрахунки тепломасообмінних апаратів. Навч. посібник / М.М. Чепурний, С.Й. Ткаченко. Вінниия: BHTY, 2006. $130 \mathrm{c}$. 
ВІСНИК

ОДЕСЬКОГО НАЦІОНАЛЬНОГО

МОРСЬКОГО УНІВЕРСИТЕТУ

№ 2 (59), 2019
HERALD

OF THE ODESSA NATIONAL

MARITIME UNIVERSITY

4. Справочник по теплообменникам: В 2-х т. Т. 2: Пер. с англ./ Под ред. О.Г. Мартыненко и др. М.: Энергоатомиздат, 1987. $352 \mathrm{c}$.

5. Кулиниченко В.Р. Справочник по теплообменным расчетам / В.Р. Кулиниченко. К.:Техника, 2009. 165 c.

6. Потапкин В.О. Методика подбора и расчета пластинчатых теплообменников для тепловых пунктов систем теплоснабжения / В.О. Потапкин, С.В. Кунгуриев, А.Н. Букашев. Новосибирск: ОАО «Новосибирскгортеплоэнерго»,

7. В006в 54 сА.И. Расчет и сравнение характеристик пластинчатых теплообменников / А.И. Мохов, Т.А. Рафальская // Молодой ученьй. 2015. № 7. С. 176-180.

8. Аракелян С.М. Методы вычислительной гидродинамики в расчетах движения жидкости в системах со сложной тополо-гией: Учебн. пособие / С.М. Аракелян и др. Владимир: Изд-во ВлГУ, 2015. $99 \mathrm{c.}$.

9. Горшенин А.С. Методы интенсификации теплообмена:Учебн. пособие. Самара: Самар.гос.техн.ун-т., 2009. 82 с.

10. Светлов Ю.В. Интенсификация гидродинамических и тепловых прочессов в аппаратах с турбулизаторами потока. Теория, эксперимент, методы расчета. М.: Энергоатомиздат, 2003. $304 \mathrm{c}$.

11. Веселовський В.Б. Математичне моделювання та методи розрахунку теплотехнологічних прочесів: Навч. посібник / В.Б. Веселовський, А.Ю. Дреус, А.В. Сясєв. Д.: Вид-во Дніпponemp. yн-my, 2004. $248 \mathrm{c.}$

12. Карякин В.Е. Расчет течений вязкой жидкости в плоских каналах произвольной формы / В.Е. Карякин, Ю.Е. Карякин // Численные методы механики сплошной среды. Новосибирск, 1986. T. 17. № 5. C. 91-100.

13. Stoitchkov N.J., Dimirov G.J. Effectiveness of crossflow plate heat exchanger for indirect evaporative cooling / N.J. Stoitchkov, G.J. Dimirov // Int. J. Refrig. 1998. Vol. 21. № 6. P. 463- 471.

14. Меркт Р.В. Оптимизация воздухоохладителей испарительного типа / Р.В. Меркт, В.В. Челабчи, В.Н. Челабчи // Промышленная теплотехника. 2003. Т. 25. № 4. С. 167-169.

15. Челабчі В.Н. Моделювання розгалужених суднових систем / Т.Д. Панченко, В.В. Челабчі, В.Н. Челабчі // Вісник Одеського національного морського університету: Зб. наук. праць. Odeca: OHMУ, 2016. № 3(49). C. 104-115. 
16. Merkt R.V. Computer simulation of associated transfer processes / R.V. Merkt, V.V. Chelabchy // Вестник Национального технического университета «ХПИ». Сборник научных трудов. Тематический выпуск «Системный анализ, управление и информационные технологии». Харьков. 2004. № 2. С. 37-

17. Жеркт Р.В. Особенности моделирование переходных режимов течения в каналах / Р.В. Меркт, В.В. Челабчи, В.Н. Челабчи // Сб. научн. трудов международной научно-практической конференции "Современные направления теоретических и прикладных исследований '2010». Одесса: Черноморье, 2010. T. 34. C. 16-20.

18. Патанкар С.В. Численные методы решения задач теплообмена и динамики жидкости / С.В. Патанкар. М.: Энергоатомиздат, 1984. 152 c.

19. Chelabchi V.V. Mathematical modeling of air coolers of indirect evaporative type / V.V. Chelabchi // Восточно-европейский журнал передовых технологий. Харьков, 2017. № 1/1(85). С.

20. Bthellabchi V.N. Smoothing out of experimental dependences / V.N. Chelabchi, V.V. Chelabchi // Cб. научн. трудов Sword. Иваново: МАРКОВА АД, 2013. Вып. 4. Т. 5. С. 47-51.

\section{REFERENCES}

1. Doroshenko A.V., Kyryllov V.Kh., Efymova O.V., Klymchuk A.A. (2000) Novoe pokolenye system kondytsyonyrovanyya vozdukha na osnove kombynyrovannblkh ysparytel'nblkh okhladyteley [The new generation of air conditioning systems based on combined evaporative coolers]. Refrigeration and Technology, no. 67, pp. 57-68.

2. Merkt R.V., Chelabchi V.N. (1993) Ecologically clean coolproduction on ships. Proceedings of the 6-th Congress of the IMAM, vol. 3, pp. 173-179.

3. Chepurnyi M.M., Tkachenko S.Y. (2006) Rozrakhunky teplomasoobminnykh aparativ. Navch. Posibnyk [Calculations of heat exchangers. Educ. manual]. Vinnytsia: VNTU. (in Ukrainian)

4. Martynenko O.H. (1987) Spravochnik po teploobmennikam [Heat Exchanger Reference]. Moskow: Energoatomizdat. vol. 2. (in Russian).

5. Kulinichenko V.R. (2009) Spravochnik po teploobmennym raschetam [Heat Exchange Calculator Reference]. Kiev: Technique. (in Russian). 
6. Potapkin V.O., Kungurcev S.V., Bukashev A.N. (2006) Metodika podbora i rascheta plastinchatyh teploobmennikov dlya teplovyh punktov sistem teplosnabzheniya [Methods of selection and calculation of plate heat exchangers for heat points of heat supply systems]. Novosibirsk: JSC «Novosibirskgorteploenergo» (in Russian).

7. Mohov A.I., Rafalskaya T.A. (2015) Расчет и сравнение характеристик пластинчатых теплообменников [Calculation and comparison of characteristics of plate heat exchangers]. Young scientist, no. 7, pp. 176-180.

8. Arakelyan S.M. (2015) Metody vychislitelnoj gidrodinamiki $v$ raschetah dvizheniya zhidkosti $v$ sistemah so slozhnoj topolo-giej: Uchebn. posobie [Methods of computational fluid dynamics in the calculation of fluid motion in systems with complex topology: Educ. manual]. Vladimir: VISU Publishing House

9. Gorshenin A.S. (2009) Metody intensifikacii teploobmena:Uchebn. posobie. [Methods of intensification of heat transfer: Educ. manual]. Samara: Samar.gos.tekhn.un-t (in Russian).

10. Svetlov Yu.V. (2003) Intensifikaciya gidrodinamicheskih i teplovyh processov $v$ apparatah $s$ turbulizatorami potoka. Teoriya, eksperiment, metody rascheta [Intensification of hydrodynamic and thermal processes in devices with flow turbulators. Theory, experiment, calculation methods]. Moskow: Energoatomizdat (in Russian).

11. Veselovskij V.B., Dreus A.Yu., Syasyev A.V. (2004) Matematychne modeliuvannia ta metody rozrakhunku teplotekhnolohichnykh protsesiv: Navch. posibnyk [Mathematical Modeling and Methods of Calculation of Thermal Technology Processes: Educ. manual] (in Russian).

12. Karyakin V.E., Karyakin Yu.E. (1986) Raschet techenij vyazkoj zhidkosti $v$ ploskih kanalah proizvolnoj formy [Calculation of viscous fluid flows in planar channels of arbitrary shape]. Numerical methods for continuous medium mechanics, vol. 17, no. 5, pp. 91-100.

13. Stoitchkov N.J., Dimirov G.J. (1998) Effectiveness of crossflow plate heat exchanger for indirect evaporative cooling. Int. J. Refrig, vol. 21, no. 6, pp. 463-471.

14. Merkt R.V., Chelabchi V.V., Chelabchi V.N. (2003) Optimizaciya vozduhoohladitelej isparitelnogo tipa [Evaporative Air Cooler Optimization]. Industrial heat engineering, vol. 25, no. 4, pp. 167-169. 
15. Panchenko T.D., Chelabchi V.V., Chelabchi V.N. (2016) Modeliuvannia rozghaluzhenykh sudnovykh system [Modeling of branched ship systems]. Visnyk Odeskoho natsionalnoho morskoho universytetu: Zb. nauk. prats, vol. 49, no. 3, pp. 104-115.

16. Merkt R.V., Chelabchy V.V. (2004) Computer simulation of associated transfer processes. System analysis, management and infor-mation technology, no. 2, pp. 37-47.

17. Merkt R.V., Chelabchy V.V., Chelabchy V.N. (2010) Osobennosti modelirovanie perehodnyh rezhimov techeniya $v$ kanalah [Features modeling of transitional flow regimes in channels]. Sat scientific Proceedings of the International Scientific and Practical Conference "Modern Directions of Theoretical and Applied Research'2010», vol. 34, pp. 16-20.

18. Patankar S.V. (1984) Численные методы решения задач теплообмена и динамики жидкости [Numerical methods for solving heat transfer and fluid dynamics problems]. Moskow: Energo-atomizdat (in Russian).

19. Chelabchi V.V. (2017) Mathematical modeling of air coolers of indirect evaporative type. East European Journal of Advanced Technology, vol. 85, no. 1, pp. 34-42.

20. Chelabchy V.V., Chelabchy V.N. (2013) Smoothing out of experimental dependences. Sat scientific Proceedings of Sworld, vol. 5, no. 4, pp. 47-51.

Стаття надійшла до редакиії 30.06.2019

\section{Рецензенти:}

доктор технічних наук, професор, віце-президент Асоціації Українського сейсмостійкого будівництва, директор Науково-дослідного інституту фундаментальних і прикладних досліджень Одеського національного морського університету К.В. Єгупов

старший викладач кафедри «Технічна кібернетика та інформаційні технології ім. проф. Р.В. Меркта» Одеського національного морського університету І.С. Рубльов 